\title{
EXPERIMENTAL AND CLINICAL EVALUATION OF A NEW SYNTHETIC, ABSORBABLE SEALANT TO REDUCE AIR LEAKS IN THORACIC OPERATIONS
}

Paolo Macchiarini, $\mathrm{MD}, \mathrm{PhD}^{\mathrm{a}}$

John Wain, MD

Susan Almy, MS

Philippe Dartevelle, MD
Background: Air leaks after pulmonary resections may contribute to increased patient morbidity, delayed removal of chest drainage tubes, and prolonged hospitalization. Objective: The purpose of this study was to investigate the effects of a new synthetic, absorbable sealant on the healing of healthy bronchial and lung tissues (experimental study) and its safety and efficacy to stop air leaks after lung resection (clinical study). Methods: Fifteen large white pigs underwent a left upper lobectomy. All parenchymal surgical sites were sealed; the bronchial stump was either stapled, sealed, or both ( $n=5$ each). In the clinical study, 26 consecutive patients were prospectively randomized, intraoperatively, to standard closure of parenchymal surgical sites with $(n=15)$ or without ( $n=11)$ the sealant. Results: In the experimental study, no postoperative air leaks occurred, with intact bronchial closures and normal tissues at death. In the clinical study, $\mathbf{1 0 0 \%}$ of intraoperative leaks were sealed versus $18 \%$ of control patients $(P=.001)$. Although $77 \%(n=10)$ of treated patients remained leak-free from the end of the operation to chest tube removal versus $9 \%(n=1)$ of control patients $(P=.001)$, there was no statistical difference in the duration of postoperative chest tube time, hospital stay, or cost. There were no acute or late undesirable sideeffects related to the sealant application. Conclusions: The surgical adhesive investigated here demonstrated a compelling safety profile and significant clinical efficacy to stop air leaks after lung resections. (J Thorac Cardiovasc Surg 1999;117:751-8)
A ir leaks occur at pulmonary tissue sites that have been dissected during surgical resection and/or manipulation. Most small-flow air leaks, resulting from inaccurate or unsuccessful closure of distal bronchioles or alveolar spaces, are innocuous and of short duration. ${ }^{1,2}$ Persisting excessive air leaks, however, represent a major complication because they extend chest tube drainage, length of hospital stay, overall morbidity, and health care costs. ${ }^{1-5}$

From the Departments of Thoracic and Vascular Surgery and HeartLung Transplantation, Marie-Lannelongue Hôpital, Paris-Sud University, Le Plessis Robinson, Francea; Thoracic Surgery, Harvard Medical School, Massachusetts General Hospital, Boston, Mass $^{\mathrm{b}}$; and Statistics Unlimited, Inc, Westford, Mass. ${ }^{\mathrm{c}}$

Received for publication July 24, 1998; revisions requested Oct 30, 1998; revisions received Nov 23, 1998; accepted for publication Nov 23, 1998.

Address for reprints: Paolo Macchiarini, MD, PhD, Department of Thoracic and Vascular Surgery, Heidehaus Hospital (Hannover Medical School), 70, Leineufer, D-30419, Hannover, Germany. Copyright $\odot 1999$ by Mosby, Inc.

$0022-5223 / 99 \$ 8.00+0 \quad \mathbf{1 2 / 1 / 9 6 2 0 6}$
Recently, a new synthetic, absorbable surgical sealant has proved biocompatibility and effectiveness as a dural $^{6}$ and lung ${ }^{7}$ sealant in a canine model. On this basis, we first investigated the effects of this adhesive on healthy bronchial and lung tissues in a pig model and then conducted a prospective randomized clinical study, investigating the safety and efficacy of this adhesive to reduce parenchymal air leaks after lung resections.

\section{Materials and methods}

Experimental study. Fifteen large white pigs (25-40 kg) underwent a left upper lobectomy, performed by 2 of us (P.M. and J.W.). The lung fissure was always stapled, and all areas of parenchymal dissections were treated with the surgical sealant; the bronchial stump was randomly stapled (group 1), stapled and sealed (group 2), or sealed only (group 3). Each study group included 5 animals. All animals received care in compliance with the "Principles of Laboratory Animal Care" formulated by the National Society for Medical Research and the "Guide for the Care and Use of Laboratory Animals" formulated by the National Academy of Sciences (NIH publication No. 85-23, revised 1985).

General anesthesia was induced with ketamine hydrochlo- 

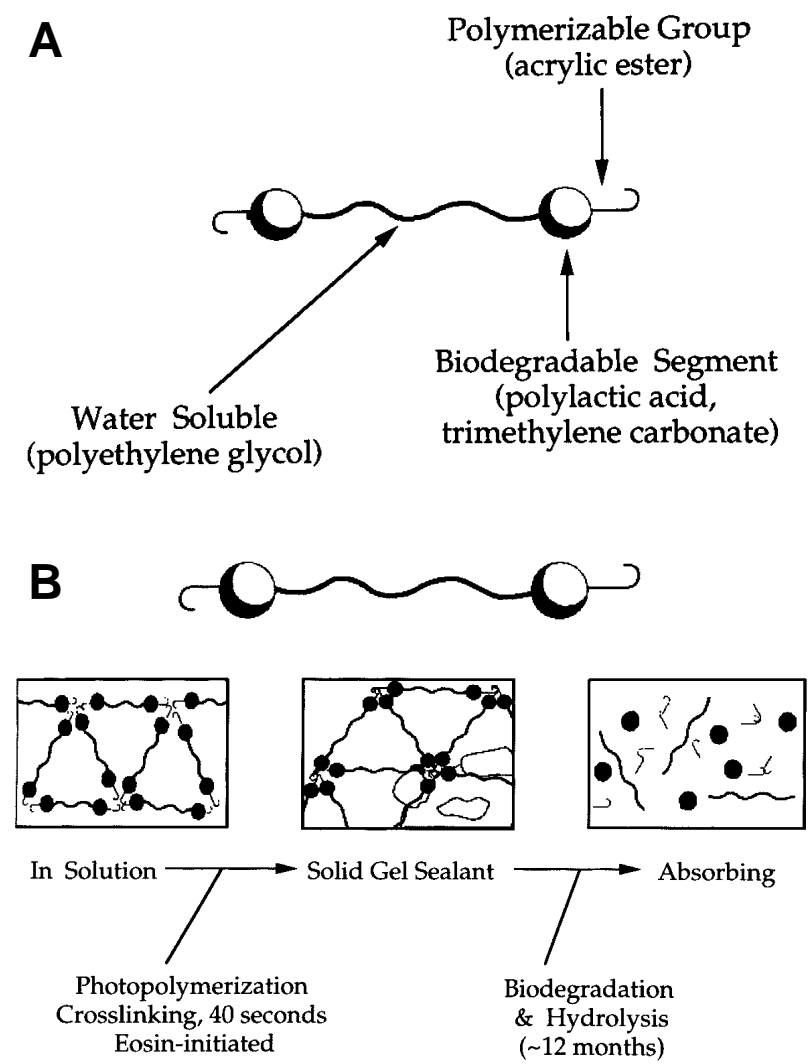

Fig 1. The surgical sealant components (A) and life cycle (B).

ride (20 mg/kg intramuscularly) and inhalation of isoflurane by mask as needed to enable endotracheal intubation. A surgical plane of anesthesia was maintained using isoflurane (1\%-3\% as needed) delivered through a semiclosed rebreathing system. Perioperative antibiotics (cefazolin, $22 \mathrm{mg} / \mathrm{kg}$ intravenously) were initiated at induction. Lactated Ringer's solution was given at $22 \mathrm{mg} / \mathrm{kg} / \mathrm{h}$ through a marginal ear vein during the surgical procedure. The animals were positioned in right lateral decubitus position, and the thoracic cavity was entered through the fourth intercostal space. The fissure between the left upper and lower lobes was divided with a linear cutting stapler (TA 55; United States Surgical Corporation, Auto Suture Company Division, Norwalk, Conn); the vascular supply was ligated, and the left upper lobe bronchus was divided. Depending on study group, the bronchus was either stapled with a 30-mm mechanical stapler (groups 1 and 2) or incised primarily approximately $4 \mathrm{~mm}$ from the lobar take-off origin (group 3). Group 1 animals received no additional treatment after the stapling of the bronchial stump. Group 2 animals had approximately 2 to 3 $\mathrm{mL}$ of hydrogel sealant applied and polymerized over the staple closure. Group 3 animals had no suture or staple closure and had a 4 to $5 \mathrm{~mm}$ open bronchial stump into which 2 to 3 $\mathrm{mL}$ of hydrogel sealant was applied and polymerized. All bronchial closures were leak tested to $40 \mathrm{~cm} \mathrm{H}_{2} \mathrm{O}$, the tho- racic cavity was thoroughly lavaged, fluid was evaluated, a $16 \mathrm{~F}$ chest tube was placed, and the wound was closed in layers. The chest tube was intermittently monitored for air and fluid output over 48 hours. Thoracic radiographs were taken on postoperative days 3 and 5. Postoperative oral cephalosporin antibiotics were continued for 7 days. Animals were killed at 6 weeks; the trachea was harvested at the origin of the left upper lobe bronchus, and porcine tissues were paraffin embedded, processed, and stained with hematoxylin and eosin.

Clinical study. This open-labeled, randomized study was conducted in accordance with the Medical Device Directive and the European Standard (EN 540) for clinical investigation of medical devices for human subjects (British Standards Institution publication, 615.471: 615.478: 620.1; 1993, pp. 62-78). The protocol was approved by the Paris-Sud University and Marie-Lannelongue Ethics Committees and operations were made by 2 of us (P.M. and P.D.). All consecutive patients scheduled for pulmonary lobectomy or lesser resection by a thoracotomy between July 1996 and January 1997 were screened for eligibility to enter the study within 2 weeks of their operation; witnessed, informed consent was obtained before the procedure. Inclusion criteria included age ( $\geq 18$ years); platelets $\left(\geq 100,000\right.$ cells $\left./ \mathrm{mm}^{3}\right)$; alanine aminotransferase, aspertate aminotransferase, and alkaline phos- 
Table I. Intraoperative characteristics of the experimental study*

\begin{tabular}{lccc}
\hline Characteristics & Group I & Group II & Group III \\
\hline Weight $(\mathrm{kg})$ & $22 \pm 2$ & $21 \pm 2$ & $20 \pm 2$ \\
Left upper lobe surface $\left(\mathrm{cm}^{3}\right)$ & $1 \pm 0.1$ & $1 \pm 0.1$ & $0.9 \pm 0.1$ \\
$\begin{array}{l}\text { Left upper lobe stump length } \\
\quad(\mathrm{cm})\end{array}$ & 1.5 & $1.3 \pm 0.4$ & $1.5 \pm 0.3$ \\
Light cycles & & & \\
$\quad$ Lung stapler line & $2 \pm 1$ & $2 \pm 1$ & $3 \pm 1$ \\
Bronchial stump & - & $3 \pm 1$ & $2.4 \pm 0.5$ \\
\hline
\end{tabular}

*Each study group included 5 animals.

Table II. Baseline characteristics of patients included in clinical study

\begin{tabular}{lccc}
\hline Characteristics & $\begin{array}{c}\text { Treatment } \\
(n=13)\end{array}$ & $\begin{array}{c}\text { Control } \\
(n=11)\end{array}$ & P value \\
\hline Gender & & & \\
$\quad$ Male (\%) & $9(69)$ & $9(82)$ & .65 \\
$\quad$ Female (\%) & $4(31)$ & $2(18)$ & \\
Age (mean \pm SD y) & $61 \pm 10.3$ & $59 \pm 15.4$ & .93 \\
Chronic obstructive (+ vs -) & 2 vs 11 & 0 vs 11 & .48 \\
$\quad$ pulmonary disease & & & \\
Chronic bronchitis (+ vs -) & 1 vs 12 & 0 vs 11 & 1.0 \\
Emphysema (+ vs -) & 0 vs 13 & 1 vs 10 & .46 \\
Primary diagnosis & & & .46 \\
$\quad$ Bronchogenic carcinoma & $9(69)$ & $7(64)$ & \\
$\quad(\%)$ & & & \\
$\quad \begin{array}{l}\text { Pulmonary metastases (\%) } \\
\text { Benign neoplasm (\%) }\end{array}$ & $2(15)$ & - & - \\
$\quad$ Bronchostenosis (\%) & $1(8)$ & - & \\
Tuberculosis (\%) & $1(8)$ & $1(9)$ & \\
Other (\%) & - & $1(9)$ & \\
\hline
\end{tabular}

+, Present; -, absent.

phatase levels ( $\leq 1.5$ of upper limit of normal); bilirubin level $(\leq 1.5 \mathrm{mg} / \mathrm{dL})$; creatinine level $(\leq 2.0 \mathrm{mg} / \mathrm{dL})$; prothrombin time ( $\leq 15$ seconds), and patient ability to provide informed consent. Any woman of child-bearing age required a negative pregnancy test (human chorionic gonadotropin urine or serum) within 7 days before the operation. The following patients were excluded: patients undergoing pneumonectomy, women who were pregnant or lactating, patients with a history or laboratory evidence of hemostatic abnormality or a lack of hemostasis at operation, patients not expected to be available for follow-up, patients who had undergone investigational therapy within 28 days before the operation or who were scheduled to receive such therapy within 30 days of the operation, and any patient with severe congestive heart failure, cor pulmonale, and/or renal failure.

Patients enrolled in the study underwent their scheduled thoracic procedure, during which the determination was made as to whether they remained eligible for randomization. After a lobectomy or lesser resection with standard suture and/or staple closure, all surgical sites were identified. A surgical site

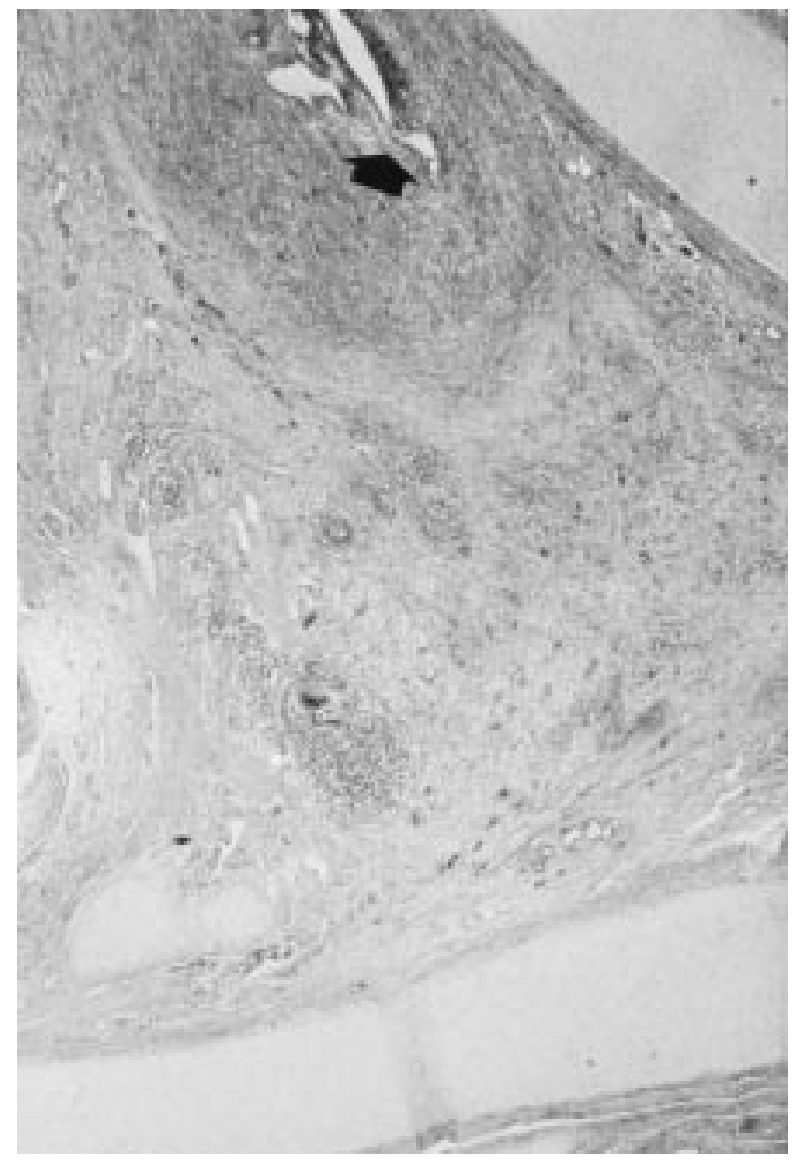

Fig 2. The section taken just proximal to the sealant plug (arrow) shows an organized fibrovascular scar that is bridging across and filling the entire bronchial lumen (note hyaline cartilage lower right and left side of frame). The sealants present right center frame surrounded by a cuff of macrophages; note the lack of foreign body giant cell formation and viable cells in contact with it. (Hematoxylin and eosin stain; original magnification, $\times 25$.)

was defined as any site that had been manipulated and was assumed to be at risk for air leakage, including all staple lines, suture lines, areas of dissection and adhesiolysis. Next, sterile saline solution was poured into the chest cavity; the lung was submerged in the saline solution to check for the presence or absence of air bubbles, and the location of each surgical site was recorded. Each surgical site was graded with the lung submersed in saline solution and inflated to pressures of 20 to 40 $\mathrm{cm} \mathrm{H}_{2} \mathrm{O}$; the presence or absence of air leaks was scored as grades 0 (no leak), 1 (countable bubbles), 2 (stream of bubbles), and 3 (coalesced bubbles). If any grade 3 leaks were identified, the investigator used suture or stapler to close the leak or at least reduce it to a lower grade; saline-solution submersion was repeated, and the final grade was recorded.

The randomization scheme was prepared by the study statistician, and the randomization for each patient was main- 
Table III. Distribution of number of surgical sites per patient

\begin{tabular}{lcc}
\hline $\begin{array}{l}\text { No. of } \\
\text { surgical sites }\end{array}$ & $\begin{array}{c}\text { Treatment } \\
(n=13)\end{array}$ & $\begin{array}{c}\text { Control } \\
(n=11)\end{array}$ \\
\hline 0 & - & - \\
1 & - & - \\
2 & - & $1(9)$ \\
$3(\%)$ & $5(38)$ & $4(36)$ \\
$4+(\%)$ & $8(62)$ & $6(55)$ \\
\hline
\end{tabular}

tained in a sealed envelope. After the grading of surgical sites for leaks, the envelopes were sequentially opened, and the patient was entered into either the treatment or control group of the study. Patients assigned to the control group received standard surgical management. Patients assigned to the treatment group had the synthetic sealant applied to all identified surgical sites (including those sites graded 0, nonleaking), excluding the bronchial stump, followed by a repeat salinesolution submersion test. If any leaks persisted or if new sites were identified, additional sealant was applied as necessary. A final submersion test was performed, and a posttreatment grade for each identified site was recorded.

On postoperative days 1, 3, 7 (and/or day of discharge), 30, and 60, all patients underwent a safety evaluation including an assessment of daily chest tube output. Safety evaluations included physical examinations to monitor for potential allergic or inflammatory reactions or compromised wound healing. Serum chemistries and hematologic parameters were used to assess renal and liver functions or any unanticipated toxicity. A further safety evaluation was made 18 months after the operation for those patients who were still alive and included all examinations mentioned.

Sealant material. The surgical lung sealant (Focal Inc, Lexington) is a synthetic absorbable biomaterial consisting of 2 components, a primer and the sealant. The primary component of the sealant is a difunctional macromonomer composed of polyethyleneglycol, linked to trimethylene carbonate moieties, which are in turn linked to acrylate endgroups (Fig 1, A). The primer is reconstituted at the time of operation and, when brushed onto the target tissue through the applicator, acts as a wetting solution to prepare the surface of tissue for good adhesion. The clear liquid polymer is delivered and mixed into the primer, then a bead of the polymer is applied from the applicator over the target tissue to form a thin coating that, when photopolymerized by visible light, forms a biocompatible, elastic hydrogel patch. Photopolymerization is accomplished by formulating the macromers in buffered saline solutions containing triethanolamine and eosin $\mathrm{Y}$ as the photoinitiator. Visible light illumination from a xenon arc lamp (470-520 nm) at an intensity of $100 \mathrm{~mW} / \mathrm{cm}^{2}$ is used to initiate polymerization for 40 seconds. The sealant is about $80 \%$ water by weight and acts as a flexible, mechanical leakage barrier for 14 days, allowing full tissue expansion and normal tissue healing at the treated site. Once implanted, the sealant material degrades by hydrolysis (Fig 1,B), releasing biocompatible components that are metabolized or cleared by the kidneys. The rates of property and mass loss are determined by the hydrolyzable linkage, and the material undergoes a characteristic and predictable breakdown pattern.

Statistics. All patients were evaluated for safety and efficacy, with the exception of the 2 pilot patients, who were evaluated for safety only. The safety profile was determined by comparing the frequency and severity of adverse device effects between treatment and control groups. The primary efficacy criteria in the prevention of air leaks was investigated by 2 outcomes: evaluation of the efficacy in sealing air leaks identified during operation and comparison of the duration of chest tube air leak between treatment and control groups. Although secondary efficacy end points included the time from operation to chest tube removal and to hospital discharge, hospitalization time, and costs, this initial study was not designed to have substantial impact on standard postoperative procedures or sufficient sample size to detect a difference between treatment and control groups with respect to the secondary end points. The sample size, calculated for the primary study end point of preventing postoperative air leaks, was based on pre-existing data ${ }^{2}$ and the hypothesis that, on a particular day (expected to be day 3 or 4), the proportion of the treatment group patients with air leaks would be reduced from $30 \%$ to $10 \%$ as compared with the control group.

All statistical comparisons were based on 2-sided $P$ values and used an $\alpha$ level of .05. Variables measured on a continuous scale were analyzed with the Wilcoxon rank sum test. ${ }^{8}$ All categoric variables were analyzed with Fisher's exact or Pearson's $\chi^{2}$ test. ${ }^{9}$ The distributions of time to last air leak sealed and time to last chest tube removal were compared with the log rank test and the generalized Wilcoxon test. ${ }^{8}$ The distributions of laboratory severity grades were analyzed with each patient's highest postoperation laboratory grade (day 1discharge). Comparisons with respect to maximum postoperation grade included only patients whose baseline value was in the normal range and were carried out with the MantelHaenszel $\chi^{2}$ test. ${ }^{10}$ The mean hospitalization cost per patient was calculated according to the French National Cost Study (DH/PMSI/92, No. 8 from February 28, 1992), which takes into account the direct expenses affected to the individual patient, expenses of the medical and technical procedures, hospitalization expenses registered in the different clinical units attended by the patient, and administrative and structural expenses. However, it does not include the costs of the sealant, which is distributed in Europe for the reduction of air leaks after pulmonary operation by Ethicon, Inc (Johnson \& Johnson; AdvaSeal) at approximately $\$ 450$ per kit; the equipment is provided free of charge.

The manufacturer (Focal, Inc) provided customary financial support only to offset the administrative costs of conducting this study.

\section{Results}

Experimental study. The intraoperative characteristics were not significantly different among the 3 groups 
Table IV. Distribution of leaks by surgical sites (before randomization)

\begin{tabular}{|c|c|c|c|c|c|c|}
\hline Type of leak & Treatment sites ( $n$ ) & Leaks* $^{*}(n)$ & Control sites $(n)$ & Leaks† (n) & Total sites $(n)$ & Leaksł $(n)$ \\
\hline Staple line $(\%)$ & 30 & $13(43)$ & 35 & $15(43)$ & 65 & $28(43)$ \\
\hline Suture line $(\%)$ & 3 & $2(67)$ & 2 & $1(50)$ & 5 & $3(60)$ \\
\hline Area of dissection (\%) & 22 & $14(64)$ & 10 & $5(50)$ & 32 & $19(59)$ \\
\hline Other & 2 & - & - & - & 2 & - \\
\hline TOTAL (\%) & 57 & $29(51)$ & 47 & $21(45)$ & 104 & $50(48)$ \\
\hline
\end{tabular}

$*_{\mathrm{n}}=13$.

$\dagger \mathrm{n}=11$.

$\ddagger \mathrm{n}=24$.

Table V. Distribution of prerandomization air leak grades

\begin{tabular}{lcc}
\hline Grade & $\begin{array}{c}\text { Treatment } \\
(n=13)\end{array}$ & $\begin{array}{c}\text { Control } \\
(n=11)\end{array}$ \\
\hline $0(\%)$ & $28(49)$ & $26(55)$ \\
$1(\%)$ & $12(21)$ & $15(32)$ \\
$2(\%)$ & $17(30)$ & $6(13)$ \\
\hline
\end{tabular}

Table VI. Chest tube and hospital data

\begin{tabular}{lccc}
\hline & $\begin{array}{c}\text { Treatment } \\
(n=13)\end{array}$ & $\begin{array}{c}\text { Control } \\
(n=11)\end{array}$ & P values \\
\hline $\begin{array}{c}\text { Time from operation to } \\
\text { last air leak sealed (d) }\end{array}$ & $1.9 \pm 1.2$ & $2.4 \pm 1.7$ & .2 \\
$\begin{array}{c}\text { Time to removal of last } \\
\text { chest tube (d) }\end{array}$ & $6.1 \pm 0.8$ & $6.9 \pm 1.5$ & .9 \\
$\begin{array}{c}\text { Chest tube drainage } \\
\text { per day (mL) }\end{array}$ & $213.2 \pm 31.1$ & $91 \pm 23.3$ & .6 \\
$\begin{array}{l}\text { Hospitalization time (d) } \\
\text { Hospitalization cost (\$) }\end{array}$ & $12,374 \pm 2.5$ & $14.4 \pm 5.2$ & .4 \\
\hline
\end{tabular}

Data are expressed as mean \pm standard deviation. The calculation of the hospital costs per day was made by taking $\$ 1$ as 5.983 francs (June 10, 1998).

(Table I). None of the animals experienced infection, dyspnea, or discomfort during the study period. No postoperative air leaks occurred. Endoscopically, the bronchial stumps showed mucosal apposition with no evidence of fistulas in groups 1 and 2. Group 3 animals showed an intact and clear, visible sealant that was tightly adherent to the bronchial mucosa on days 3 and 5; a neomucosa had formed across its surface re-establishing mucosal continuity of the bronchial stump on day 42 .

Group 1 and 2 histopathologic examination showed a fibrous union of the bronchial walls and a healed mucosa, with no difference in the degree of inflammation or quality of the healed bronchial closure. Tissues examined from group 3 showed that a fibrous scar developed over the sealant on both the bronchial and
Table VII. Laboratory severity grades after operation (among patients with normal baseline values)

\begin{tabular}{|c|c|c|c|}
\hline $\begin{array}{l}\text { Highest } \\
\text { postoperative } \\
\text { grade }\end{array}$ & $\begin{array}{c}\text { Treatment } \\
(\%)\end{array}$ & $\begin{array}{c}\text { Control } \\
(\%)\end{array}$ & $\begin{array}{c}\text { Mantel-Haenszel } \\
\text { P value }\end{array}$ \\
\hline $\mathrm{AP}$ & & & .08 \\
\hline 0 & $6(43)$ & $10(91)$ & \\
\hline 1 & $7(50)$ & - & \\
\hline 2 & $1(7)$ & $1(9)$ & \\
\hline 3 & - & - & \\
\hline 4 & - & - & \\
\hline AST & & & .8 \\
\hline 0 & $6(43)$ & $8(73)$ & \\
\hline 1 & $8(57)$ & $1(9)$ & \\
\hline 2 & - & $1(9)$ & \\
\hline 3 & - & - & \\
\hline 4 & - & $1(9)$ & \\
\hline ALT & & & .8 \\
\hline 0 & $8(53)$ & $6(67)$ & \\
\hline 1 & $5(33)$ & $2(22)$ & \\
\hline 2 & $2(13)$ & - & \\
\hline 3 & - & - & \\
\hline 4 & - & $1(11)$ & \\
\hline Creatinine & & & .2 \\
\hline 0 & $15(100)$ & $8(89)$ & \\
\hline 1 & - & $1(11)$ & \\
\hline 2 & - & - & \\
\hline 3 & - & - & \\
\hline 4 & - & - & \\
\hline
\end{tabular}
aminotransferase.

pleural space surfaces. This fibrous tissue joined the mucosal/submucosal layers across the hydrogel-filled space between the bronchial walls. The sealant was still present at 6 weeks and showed no cellular or microbial ingrowth; the interface between the tissue and sealant showed scattered, individual macrophages in contact with the sealant surrounded by a 6- to 10-cell layer of fibrovascular tissue (Fig 2). No foreign body giant cells, polymorphonuclear leukocytes, or lymphocytes were evident. A bridging neomucosa was present lying 


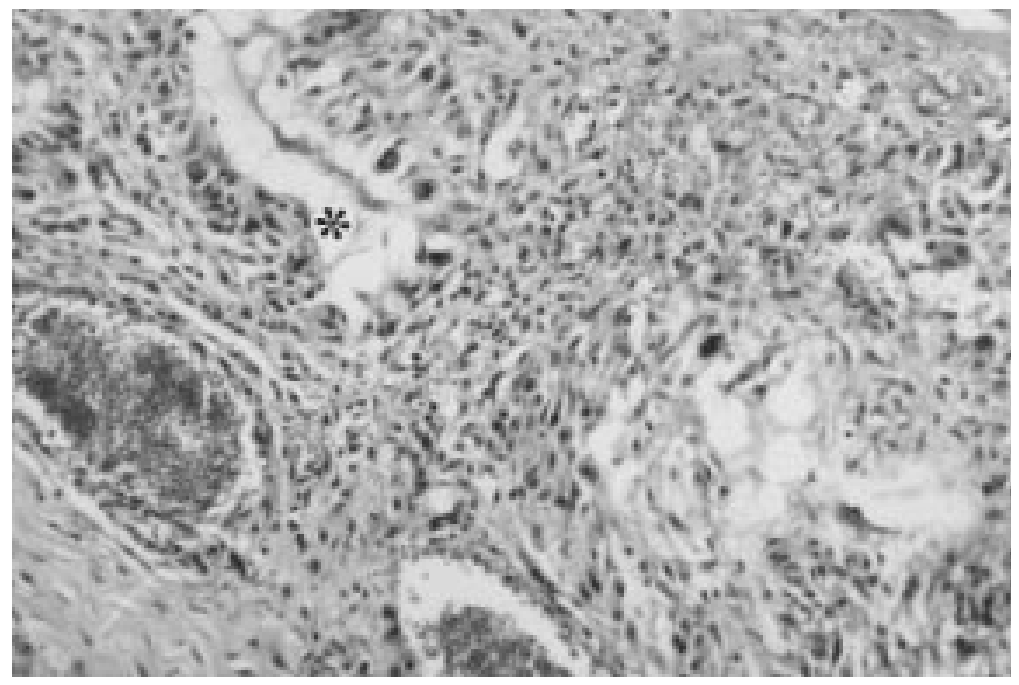

Fig 3. High-power field of the inflammatory reaction against the sealant 19 days after the operation. As in our preclinical experience, the sealant $(*)$ was surrounded by a cuff of large macrophages, fibroblasts, and lymphocytes. (Hematoxylin and eosin stain; original magnification, $\times 40$.)

on and supported by the thin fibrovascular tissue in contact with the hydrogel.

Clinical study. During the study period, a total of 30 patients were eligible for enrollment in the study; 4 patients $(13 \%)$ were ineligible because they required a pneumonectomy. Of the remaining 26 patients, 15 patients were assigned to the treatment ( 2 pilot patients and 13 randomized patients), and 11 patients were assigned to the control group; the two groups were comparable according to their baseline characteristics (Table II).

Lobectomy was the primary procedure for both groups (10 treatment and 3 control), followed by 1 treatment bilobectomy and 5 wedge resections ( 2 treatment and 3 control). Overall, there was no statistically significant difference between the treatment and control groups with respect to the number of surgical sites per patient $(P=.83$; Table III). After the baseline saline-solution submersion test and reduction of grade 3 leaks before the randomization, only 1 patient $(8 \%)$ in the treatment group and 2 patients $(18 \%)$ in the control group had no air leaks $(P=.58)$. Table IV shows that staple-line leaks $(43 \%)$ were less frequently observed than suture-line $(60 \%)$ and dissection leaks $(59 \%)(P=$ .22). There was no statistically significant difference in the overall distribution of prerandomization air leak grades $(P=.09$; Table $\mathrm{V})$.

Surgical time, excluding the surgical sealant application time, did not significantly differ between the treatment and control groups $(142 \pm 13$ minutes vs $114 \pm 11$ minutes; $P=.14)$. The average amount of primer and sealant applied per patient was $2.2 \pm 1.5 \mathrm{~mL}$ and $6.2 \pm$ $4.1 \mathrm{~mL}$, respectively; and the average application time was $15 \pm 4.8$ minutes. Intraoperative leaks were sealed in $100 \%$ of treatment group patients versus $18 \%$ of control group patients $(P=.001)$. Postoperative chest tube monitoring revealed that $77 \%(\mathrm{n}=10)$ of treatment group patients remained leak free from the end of the operation to chest tube removal versus $9 \%(\mathrm{n}=1)$ of control group patients $(P=.001)$. The proportion of patients still experiencing leakage in the treatment group was significantly $(P=.02)$ lower immediately after the operation, but this difference was not significant at later times $(P=.27)$. Treatment group patients had a nonsignificant tendency to a shorter chest tube time and hospitalization time and costs (Table VI).

A transient increase in alkaline phosphatase, aspartate aminotransferase, alanine aminotransferase, and creatinine levels was noted; all increases resolved without additional intervention or treatment. When comparing the treatment and control groups with respect to highest postoperation laboratory grade (excluding patients with abnormal baseline values), no statistically significant differences were found for any of the laboratory parameters (Table VII). There was no in-hospital death. A major complication included 1 case $(3.8 \%)$ of emphyema (Pseudomonas aeruginosa) resulting in an early bronchopleural fistula in a pilot group patient. After an open window thoracostomy, a completion pneumonectomy was necessary because of the erosion 
of the pulmonary artery stump, but no evidence was found to relate this complication to the application of the sealant (Fig 3). At long-term follow-up (18 months), there were no clinical, radiologic, or biologic signs of adverse reactions related to the sealant application.

\section{Discussion}

An ideal sealant would incorporate a synthetic material, avoiding the immunogenicity and risks of disease transmission associated with human- or animal-sourced material such as fibrin- or collagen-based products. For use on pulmonary tissue, it would also allow for expansion, resulting in a uniform surface load on the lung and decreasing the potential for "secondary" tearing of friable tissue adjacent to a treated site. It should also be strong enough to remain sealed, withstanding normally expected pressures of a lung inflated to 30 or $40 \mathrm{~cm}$ $\mathrm{H}_{2} \mathrm{O}$. It would be easy to apply and could be used to treat air leaks from staple lines, sutures, and areas of dissection not amenable to suture or staple closure.

The sealant evaluated in this study is totally synthetic and adheres well to the applied tissues. The hydrogel is polymerized in situ with 2 parts, a primer and a sealant, as a laminate, forming a highly adherent coating of any desired thickness on the tissue. A laminate structure is used to provide good bonding to tissue (primer layer) and good mechanical properties (sealant layer) for sealing the leak and maintaining the seal during lung movement. The materials are applied to tissue in aqueous solution formulations. The primer solution is first brushed onto the tissue. The brushing action allows the primer material to obtain good intimate contact with the tissue surface, replacing the surface moisture. The sealant material is then gently mixed with the primer with a brush to provide a transition layer between the primer and sealant layers. The final, thicker sealant layer is then flowed over the application area, and the laminate is photopolymerized. Preclinically, it was shown to adhere 4 times more and withstand pressures 12 times greater than could be tolerated by reference surgical sealant materials (Focal Inc; personal communication, 1998). Once polymerized, the sealant is clear, allowing good visualization of target tissue. It has a compliance matched to human lung tissue (28 vs $29.4 \mathrm{kPa}$, respectively) and the capability to expand to over $700 \%$ its own size, ensuring that neither the sealant nor the lung tissue is torn during respiration and that the lung tissue beneath the sealant is normally ventilated. Histologic evaluation of the immunogenicity of the sealant material has been shown in preclinical studies to be similar to that seen with suture materials. ${ }^{11}$
In the present experience, the synthetic sealant was totally effective in eliminating intraoperative air leaks. In the experimental study, the sealant was able to avoid postoperative leaks arising from the dissected lung tissues and the bronchial stumps. Interestingly, the stapled lung tissues were always normal. The bronchoscopic examinations showed an intact seal bridging the walls of the bronchial stump on days 3 and 5 after the operation and a respiratory neomucosa re-epithelializing the adhesive surface at death, with no evidence of cellular or microbial ingrowth. This and its safe biologic profile renders the investigated sealant particularly attractive for a potential clinical application in treating bronchopleural fistulas. However, a recent yet unpublished clinical study investigating the preventive effects of the sealant on the bronchial stump after lobectomy was associated with a high incidence of bronchopleural fistula. A plausible explanation of this evidence could be that the synthetic sealant applied to the bronchial stump acted as a mechanical barrier preventing adhesion formation and eliminating a natural source of revascularization, resulting in slower healing therefore favoring the genesis of bronchopleural fistula. However, our preliminary experience with patients with postpneumonectomy or postlobectomy bronchopleural fistulas is encouraging because the application of the sealant avoided the hazards of the postpneumonectomy bronchial stump mediastinal dissection ${ }^{12}$ and resulted in a long-lasting closure and no undesirable local or systemic side effects (personal communication, 1998).

In the clinical study, the sealant was easy to use and apply in all anatomic areas, did not elicit a clinically demonstrable host response, and did not result in any significant changes in laboratory parameters necessitating interventional treatment across the varied study population included in the treatment group. Intraoperatively, the material remained clear, adherent, and expandable and was able to eliminate all air leaks on normal and diseased lung tissue. After the operation, the proportion of patients who were air-leak free was significantly higher in the treatment group, suggesting that the sealant maintained its adhesive properties over time. Although there was a tendency toward a shorter chest tube time and hospitalization time and costs in treated patients, this trend did not reach statistical significance in our study. These end points are currently under clinical investigation in a large, multi-institutional trial in the United States.

In conclusion, the sealant device investigated here achieved the intended performance as a soft tissue reinforcement to be used for sealing or reducing air leaks that occur during pulmonary operation. 
We thank Chantal Verriest, Rémi Burel, Pascal Gusmini, and Hegésippe Langouste for technical contributions. We are especially grateful for the help, support, and patient care provided by the nurses, doctors, and laboratory staff of the MarieLannelongue Hospital.

\section{REFERENCES}

1. Kirsh MM, Rotman H, Behrendt DM, Orringer MB, Sloan H. Complications of pulmonary resection. Ann Thorac Surg 1975; 20:215-36.

2. Rice TW, Kirby TJ. Prolonged air leak. Chest Surg Clin North Am 1992;2:803-11.

3. Keagy BA, Lores ME, Starek PJK, Murray GF, Lucas CL, Wilcox BR. Elective pulmonary lobectomy: factors associated with morbidity and operative mortality. Ann Thorac Surg 1985;40:349-52.

4. Duque JL, Ramos G, Castrodeza J, et al. Early complications in surgical treatment of lung cancer: a prospective, multicenter study. Ann Thorac Surg 1997;63:944-50.

5. Cooper JD. Technique to reduce air leaks after resection of emphysematous lung. Ann Thorac Surg 1994;57:1038-9.
6. Alleyene CH Jr, Cawley CM, Barrow DL, et al. Efficacy and biocompatibility of a photopolymerized, synthetic, absorbable hydrogel as a dural sealant in a canine craniotomy model. J Neurosurg 1998;2:308-13.

7. Ranger WR, Halpin D, Sawhney AS, Lyman M, LoCicero J. Pneumostasis of experimental air leaks with a new photopolymerized synthetic tissue sealant. Am Surg 1997;63:788-95.

8. Woolson RF. Statistical methods for the analysis of biomedical data. New York: John Wiley \& Sons; 1987.

9. Lawless JE. Statistical models and methods for lifetime data. New York: John Wiley \& Sons; 1982.

10. Mantel N, Haenszel W. Statistical aspects of the analysis of data from retrospective studies of disease. J Natl Cancer Inst 1959;22: $719-48$.

11. Sawhney AS, Lyman MD, Yao F, Lavine MA, Jarrett PK. A novel in situ formed hydrogel for use as a surgical sealant or barrier. Proceedings of the International Symposium on the Control of Relative Bioactivity Material. Controlled Release Society, Inc. 1996;23:236-7.

12. Wain J. Management of late postpneumonectomy empyema and bronchopleural fistula: empyema, spaces, and fistula. Chest Surg Clin N Am 1996;6:529-41.

\section{Availability of Journal back issues}

As a service to our subscribers, copies of back issues of The Journal of Thoracic and Cardiovascular Surgery for the preceding 5 years are maintained and are available for purchase from Mosby at a cost of $\$ 17.00$ per issue until inventory is depleted. The following quantity discounts are available: $25 \%$ off on quantities of 12 to 23, and one third off on quantities of 24 or more. Please write to Mosby, Inc, Subscription Services, 11830 Westline Industrial Drive, St Louis, MO 63146-3318, or call 800-453-4351 or 314-453-4351 for information on availability of particular issues. If unavailable from the publisher, photocopies of complete issues may be purchased from UMI, $300 \mathrm{~N}$ Zeeb Rd, Ann Arbor, MI 48106, 313-761-4700. 